\title{
Developmental Variation in the Structure of the Retina
}

\author{
Richard H. Masland, Joseph F. Rizzo III, and Julie H. Sandell \\ Program in Neuroscience, Harvard Medical School, Boston, Massachusetts 02114
}

\begin{abstract}
Events traditionally called "developmental errors" are known to occur in both vertebrate and invertebrate nervous systems. This study was concerned with the frequency and mode of generation of such events in the mammalian retina. We studied three anomalous structures observed in the rabbit's retina after staining of the cell populations that accumulate indoleamines: type 3 cells, stray processes in the optic fiber layer, and displaced cells. They were counted in rabbit retinas prepared as whole-mounts, and in most cases topological maps were made. For comparison, the conventional indoleamine-accumulating amacrine cells and the tyrosine hydroxylase (TH)-positive cells, which are members of the mammalian retina's recognized complement of amacrine cells, were also counted. A further comparison was made with the number and distribution of TH-positive amacrine cells in highly inbred mice.
\end{abstract}

The ordinary amacrine cells did not vary much in number from animal to animal. Especially in inbred mice, the reproducibility was striking: the extreme variation in number of TH amacrine cells between any two of the 14 retinas studied was $22 \%$, and the mean difference between two eyes of individual mice was $2.5 \pm 1.7 \%$. The three anomalous structures were rare and variable. Their numbers varied more than fourfold from animal to animal. However, their numbers in two eyes from the same animal varied by an overall average of only $14 \pm 10 \%$. The anomalous structures were present in all rabbits, and their morphology was the same in all cases: they are under precise control by the developmental program. The anomalous cells share many phenotypic features with the regular amacrine cells of the indoleamine-accumulating class. They thus appear to be the result of minor variations in the developmental control program, such that the final shape of the cell is anomalous but most other features remain the same. It appears that slight variations in the program of neuronal development can create new neuronal structures that are both intricate and highly reproducible.

[Key words: retina, development, amacrine, variation, cell numbers, histology]

Everyone who has studied the structure of the nervous system in detail has recognized the existence of rare neuronal structures that violate the expected order-they have the appearance of

\footnotetext{
Received Jan. 15, 1993; revised June 7, 1993; accepted June 10, 1993.

We thank Nancy Madigan for technical assistance. This work was supported by NIH Grants R37 EY01075 and R01 EY05747.

Correspondence should be addressed to Dr. Richard Masland, Wellman 429, Massachusetts General Hospital, Boston, MA 02114.

Copyright (C) 1993 Society for Neuroscience 0270-6474/93/135194-09\$05.00/0
}

nonsense events in an otherwise intelligible pattern of neurons and their connections. Such events are traditionally called "developmental errors" and are the subject of this article.

The subject can be stated in an alternative way: how reproducible are the neuronal ensembles of large brains? In simple animals, the genetic program produces neural structures that are virtually exact copies of each other. Are large brains similarly reproducible, or does their developmental program use different rules - rules that might sacrifice reproducibility for economy? One of our goals was to establish the frequencies of some aberrant structures present in a sample of mammalian CNS. We also compared their rate of appearance with the variability observed for cells that are clearly not "errors" in this tissue.

Most previous studies of developmental variability in mammalian nervous systems are anecdotal: developmental errors are widely observed, but little is known of their frequency or their reproducibility (see reviews by Williams and Herrup, 1988; Vaney, 1991; Wässle and Boycott, 1991). Clearer information comes from studies of simple nervous systems, where individual neurons occur with identical shape and place in all mcmbers of the species. Even in simple animals, developmental errors are seen. In their reconstruction of the nervous system of Caenorhabditis elegans, White et al. (1986) noted a branch missing from the RMFR neuron of one of the worms studied. They also observed processes traveling in inappropriate positions within the nematode's nerve cord and making inappropriate synapses there (White, 1985). Macagno (1980) studied the reproducibility of neuron number in leech segmental ganglia and found a $1-2 \%$ variation from animal to animal. Goodman (1977) studied the number of neurons in a series of parthegenogenetic clones of locusts. In one clone (an extreme example), a survey of $42 \mathrm{mem}-$ bers of the clone showed 22 instances in which the identified cell cluster "L1-3" had supernumerary neurons. It was suggested that the generation of duplicate cells is controlled by some delicately balanced developmental choice, such that "developmental noise" (Goodman, 1977) could cause the observed variation.

Taken together, these results show that variants exist even among the neurons of clonally related animals-animals in which there is little duplication of function among the few neurons that make up their nervous systems. What happens in animals that have $10^{10}$ neurons instead of $10^{3}$ ? For such a study the retina has special advantages. It is a sheet of cells, with unambiguous boundaries. Because the cells form essentially planar arrays, quantitation is relatively easy. The tissue can be stained intact, without sectioning and subsequent reconstruction. Positive markers for many subpopulations of neurons exist, and this eliminates most ambiguity about the identities and frequencies of cells. Perhaps most important, the same microcircuits are replicated in repeating arrays. The resulting cell mosaics 
have been studied in great detail (Wässle and Riemann, 1978; Wässle et al., 1978, 1981a, 1991; Brecha, 1983; Tauchi and Masland, 1984; Sandell and Masland, 1986; Masland, 1988; Tauchi et al., 1990; Vaney, 1991; Vaney et al., 1991). They are strikingly regular; for some populations a single cell out of position is instantly recognizable to even an untrained eye. On this background, anomalies of development are highlighted and can be reproducibly studied.

\section{Materials and Methods}

The retinal neurons studied were all identified by conventional histochemical methods, which have been described in detail in previous publications (Sandell and Masland, 1986, 1989; Tauchi et al., 1990). The methods will be described briefly here, together with the methods used to count and map the cells.

Type 3 cells. The densities of type 3 cells are taken from a previous study (Sandell and Masland, 1989). They are reprinted here for comparison with the densities of regular and displaced indoleamine-accumulating amacrine cells. The type 3 cells in the retinas from rabbits $1-$ 3 were labeled by exposure to 5,7-dihydroxytryptamine (5,7-DHT) by intravitreal injection or in vitro incubation, and fixed in mixed aldehydes. The type 3 cells in rabbit 4 were labeled by in vitro exposure to 5-HT, followed by immunohistochemistry with antiserum against 5-HT (Incstar) and a secondary antibody conjugated to fluorescein isothiocyanate (Cooper). The retinas were scanned in the microscope at $400 \times$ total magnification. The location of each type 3 cell was recorded by reading its $\mathrm{x}, \mathrm{y}$-coordinates from the calibrated microscope stage. From these values maps of the location of all the type 3 cells (see Fig. 3) were constructed.

Conventional indoleamine-accumulating amacrine cells. The same retinas that were prepared for counting the type 3 cells were used to estimate the peak density of regular indoleamine-accumulating amacrine cells. Both subpopulations of regular indoleamine-accumulating cells were combined for these counts. The counts were made directly from the microscope at $250 \times$ using an eyepiece containing a grid reticle (counting frame). Cells that intersected the right and bottom margins of the counting frame were excluded. Each counting frame covered 310 $\times 310 \mu \mathrm{m}$. Counts were made every $315 \mu \mathrm{m}$ in a vertical swath that extended from the optic nerve head to the ventral periphery. These counts provided a rough indication of the location of the visual streak. We then repeated the counts in the vicinity of the visual streak using the same size counting frame, but moving the stage only $100 \mu \mathrm{m}$ after each count. This means that cells were counted in overlapping counting frames. We located the peak density of cells from this overlapping series. Although it is possible that this method still underestimated the peak density, it combined a high density of sampling with the necessarily large region per sample.

Displaced indoleamine-accumulating cells. Every indoleamine-accumulating cell located in the retinal ganglion cell layer was counted in 10 pairs of retinas. The cells in rabbits $1-3$ and rabbit 5 were labeled by histofluorescence following intravitreal injection of 5,7-DHT and fixation with mixed aldehydes (Sandell and Masland, 1986, 1989). The cells in rabbits 4 and $6-10$ were labeled by intravitreal exposure to serotonin $(50 \mu \mathrm{g}$ of 5 -HT for $2 \mathrm{hr}$ ), followed by fixation and immunohistochemistry using antibodies directed against 5-HT (Incstar). The wholemount retinas were scanned at $400 \times$ and the location of each indoleamine-accumulating cell in the retinal ganglion cell layer was recorded from the $\mathrm{x}, \mathrm{y}$-coordinates on the microscope stage.

Nerve fiber layer processes. Since these processes run for a distance across the retinal surface, they could not be counted in the same way as cell bodies. Instead, the retinas were scanned in horizontal transects. The location of each process immunoreactive for 5-HT (see above) that intersected a reference line in the eyepiece reticle was recorded. A series of transects spaced at $0.5 \mathrm{~mm}$ intervals was counted, covering most of the area of retina ventral to the visual streak. Such analysis was carried out for five pairs of retinas. The frequency of intersections for each retina (Table 1) was calculated by dividing the total number of intersections by the total linear length of retina scanned.

Tyrosine hydroxylase (TH) cells. The TH-positive amacrine cells were counted in four pairs of rabbit retinas and seven pairs of $\mathrm{C} 57 \mathrm{BL} / 6 \mathrm{~J}$ mice retinas. Rabbit retinas were prepared and labeled with antibodies against TH (East Acres Biologicals or PelFreeze) as described in Tauchi et al. (1991). Mice (C57BL/6J) were obtained from Jackson Labs, deeply anesthetized, and perfused transcardially with saline followed by $4 \%$ paraformaldehyde in $0.1 \mathrm{M} \mathrm{PO}_{4}$ buffer $(\mathrm{pH} 7.4)$. The retinas were dissected and labeled as whole-mounts with antibodies against TH (East Acres Biologicals), followed by a biotinylated secondary antibody (Cooper or Jackson Immunoresearch), and avidin-biotin-peroxidase complex (Vectastain ABC, Vector Corp.) with 3,3'-diaminobenzidine (Sigma) as the chromogen. In retinas from both species all TH-positive cells were mapped by recording the location of each cell from the calibrated microscope stage. The method used to evaluate the density of THpositive cells in rabbit retinas was dictated by their density: they are too numerous for counting of each cell in a series of retinas, but few enough that a generous sampling area is required. As a compromise, the location of every TH-positive cell in a swath $5.0 \mathrm{~mm}$ wide was counted. The swath extended from dorsal to ventral periphery and was centered on the optic nerve head. The density of cells (Table 1) was established from the number of cells and an area of retina included in the swath. For mouse retinas, every $\mathrm{TH}$-positive cell in the retina was counted and mapped.

\section{Results}

A group of retinal cells can be stained selectively because they express an indoleamine transporter. When rabbit retinas are exposed to 5-HT or synthetic indoleamines, the compounds are accumulated by a subset of retinal neurons. Subsequent photooxidation or immunohistochemistry then reveals the complcte shape of the cells. The indoleamine-accumulating cells include a class of ordinary amacrine cells. These are a regularly recognized feature of the retina, and have been described in many conventional anatomical studies (Ehinger and Florén, 1976; Brecha et al., 1984; Oyster et al., 1985; Sandell and Masland, 1986; Vaney, 1986; Voigt and Wässle, 1987; Sandell et al., 1989; Tauchi et al., 1990). In addition, three unusual neural elements are observed. They have distinctive and easily recognized structures but are rare and variable. The conventional amacrine cells and the unusual elements (type 3 cells, displaced cells, and stray indoleamine-accumulating processes) are shown schematically in Figure 1. We compared the numbers and topological distributions of the unusual cells with those of the conventional amacrine cells.

\section{Type 3 indoleamine-accumulating cells}

Our initial study was of a cell that has fcatures of both horizontal cells and amacrine cells (Figs. 1, 2). The cell bodies of the type 3 cells lie at the outer margin of the inner nuclear layer, like those of horizontal or bipolar cells, and an orderly arbor of fine processes spreads radially for up to $1 \mathrm{~mm}$ from the cell bodies. However, another process descends through the inner nuclear layer and then branches horizontally within a plexus of dendrites formed by the more numerous indoleamine-accumulating amacrine cells (these are further described below).

In previous work we showed that the number of these cells varies from animal to animal, but that the number varies much less from eye to eye of the same animal (Sandell and Masland, 1989). Maps of the positions of every type 3 cell were made for a series of four retinas (Fig. 3 ). These cells are extremely rareso rare that even the wide spread of their dendrites does not cover the retina completely. The stippled areas around two of the cells show the extent of the outer plexiform layer arbor of the largest type 3 cells. Given the spacing between the type 3 cells, wide areas of retina are not covered by processes of any type 3 cell. Note that some retinas (Table 1) have even fewer type 3 cells than the ones shown in Figure 3, and that many type 3 cells have arbors narrower than the ones indicated. Furthermore, the cells are present in variable numbers, such that one retina had as many as 270 type 3 cells and another as few 
Table 1. The numbers and/or densities of all the neural elements studied

\begin{tabular}{|c|c|c|c|c|c|c|c|c|c|c|}
\hline \multirow{2}{*}{$\begin{array}{l}\text { Sub- } \\
\text { ject }^{a}\end{array}$} & \multicolumn{2}{|c|}{$\begin{array}{l}\text { Displaced cclls } \\
\text { (cells/retina) }\end{array}$} & \multicolumn{2}{|c|}{$\begin{array}{l}\text { Typc } 3 \text { cclls } \\
\text { (cells/retina) }\end{array}$} & \multicolumn{2}{|c|}{$\begin{array}{l}\text { Conventional } \\
\text { cells } \\
\left.\text { (cells } / \mathrm{mm}^{2}\right)\end{array}$} & \multicolumn{2}{|c|}{$\begin{array}{l}\text { Frequency of } \\
\text { NFL processes } \\
\text { (intersec- } \\
\text { tions } / \mathrm{mm} \text { ) }\end{array}$} & \multicolumn{2}{|c|}{ TH cells $^{a}$} \\
\hline & Left & Right & Left & Right & Left & Right & Left & Right & Left & Right \\
\hline \multicolumn{11}{|c|}{ Rabbit } \\
\hline 1 & 1076 & 1288 & 143 & 154 & 1080 & 960 & & & & \\
\hline 2 & 560 & 403 & 58 & 62 & 1025 & 1160 & & & & \\
\hline 3 & 714 & 686 & 252 & 270 & 1122 & 1190 & & & & \\
\hline 4 & 2518 & 2368 & 135 & 187 & 1290 & 1061 & & & & \\
\hline 5 & 3079 & 3482 & & & & & & & & \\
\hline 6 & 758 & 1094 & & & & & 7.02 & 8.85 & & \\
\hline 7 & 845 & 868 & & & & & 2.27 & 3.03 & & \\
\hline 8 & 3954 & 3543 & & & & & 1.08 & 1.85 & & \\
\hline 9 & 1008 & 1166 & & & & & 4.74 & 4.97 & & \\
\hline 10 & 747 & 755 & & & & & 7.57 & 6.21 & & \\
\hline 11 & & & & & & & & & 21.3 & 24.3 \\
\hline 12 & & & & & & & & & 17.4 & 17.0 \\
\hline 13 & & & & & & & & & 15.5 & 18.6 \\
\hline 14 & & & & & & & & & 16.8 & 19.2 \\
\hline \multicolumn{11}{|c|}{ Mouse } \\
\hline 1 & & & & & & & & & 460 & 464 \\
\hline 2 & & & & & & & & & 581 & 584 \\
\hline 3 & & & & & & & & & 445 & 470 \\
\hline 4 & & & & & & & & & 455 & 437 \\
\hline 5 & & & & & & & & & 501 & 514 \\
\hline 6 & & & & & & & & & 468 & 482 \\
\hline 7 & & & & & & & & & 506 & 498 \\
\hline
\end{tabular}

In some cases more than one cell class was studied in the same retina; this was not always possible because of incompatibility of the histochemical methods used as markers for the various cells. The counts of type 3 cells are taken from a previous publication (Sandell and Masland, 1989). NFL, nerve fiber layer.

- TH-immunoreactive cell counts are expressed as cells/ $\mathrm{mm}^{2}$ for rabbit retinas, and as cells/retina for mouse retinas.

as 58 (Table 1). When two eyes from the same rabbit are compared, however, the number of type 3 cells is very nearly the same (Fig. 4).

\section{Indoleamine-accumulating amacrine cells}

A large population of conventional amacrine cells also expresses an indoleamine transporter (Fig. 2). Their cell bodies lie in the amacrine cell sublayer, their dendrites descend to branch in sublayer 5 of the inner plexiform layer, and their synapses have all of the characteristic features of amacrine synapses (Sandell and Masland, 1986; Vaney, 1986; Sandell et al., 1989). The density of these cells was measured, using the peak of the visual streak as a point of reference, for the same retinas whose type 3 cells were plotted. Their number varied only slightly: the mean difference between pairs of retinas was $11.5 \%$. The true variation may well be less, because the measurement depends on identifying the peak of a rapidly changing density distribution and small errors in sampling location cause rather large changes in apparent density (see Fig. 11 of Sandell and Masland, 1986). The number of conventional indoleamine-accumulating cells did not covary with the number of type 3 cells (Fig. 4).

\section{Displaced indoleamine-accumulating cells}

Occasional indoleamine-accumulating amacrine cells have cell bodies in an ectopic position; they lie within the ganglion cell layer rather than the amacrine cell row of the inner nuclear layer
(Fig. 1). From the point of view of function, this probably makes little difference: their dendritic arbors (where synapses are made) are morphologically indistinguishable from those of the conventional indoleamine-accumulating cells and run together with them in layer 5 of the inner plexiform layer (Sandell and Masland, 1986). For present purposes, though, they were useful because their displaced cell bodies are readily recognizable. These cells were counted and mapped (Fig. 3). Their density was low (though not as low as that of the type 3 cells) and was variable, ranging from as few as 403 per retina to as many as 3954 . In two eyes from the same animal, the variation was again slight (mean, 12.4\%; Table 1). The numbers of displaced indoleamineaccumulating cells did not covary with the number of type 3 cells or the number of conventional cells (Fig. 4).

\section{TH-containing amacrine cells}

The type 3 and displaced cells are present in small numbers, and one can hypothesize that something about rarity (e.g., wide intcrccll spacing) might contribute to their variable numbers. For comparison, we studied another ordinary population of amacrine cells, those that express TH (Figs. 1, 2). These cells are highly conserved, apparently present in all mammalian retinas with a similar morphology and connectivity (Ehinger, 1976; Oyster et al., 1985; Voigt and Wässle, 1987; Tauchi et al., 1990; Mariani, 1991). The number of TH-positive cells is roughly 8000 per rabbit retina, more than the displaced and type 3 cells 


\section{Conventional amacrine cells}

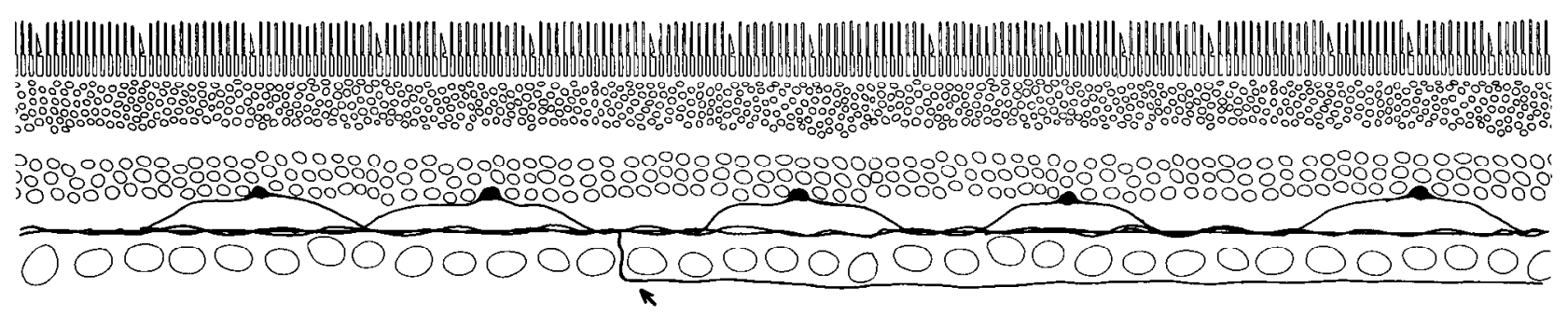

Type 3 cells

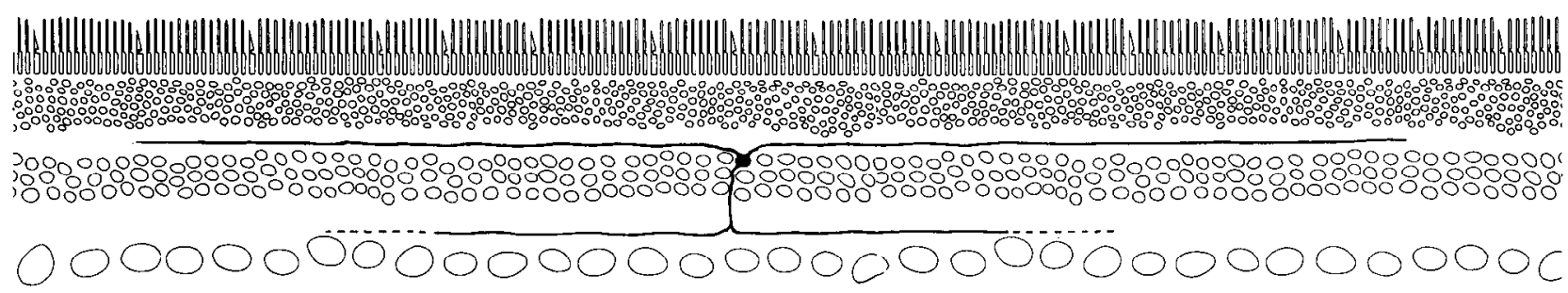

Displaced cells

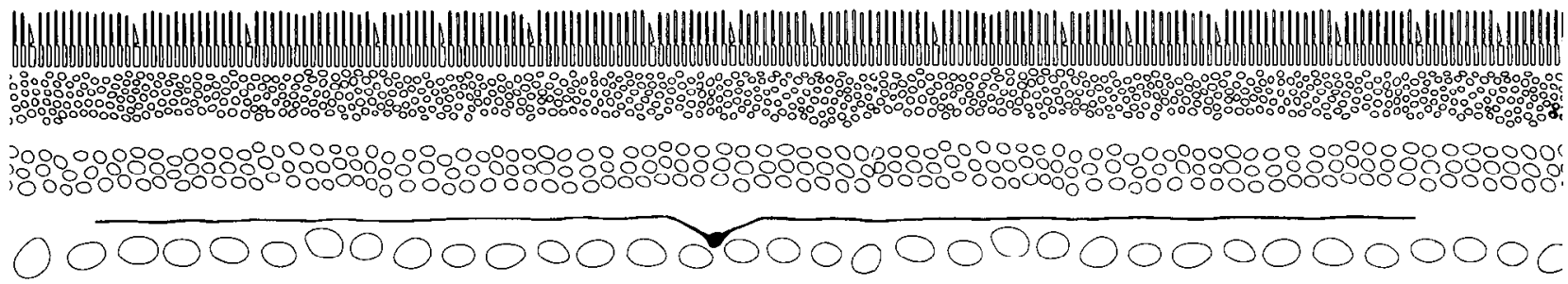

TH-positive cells

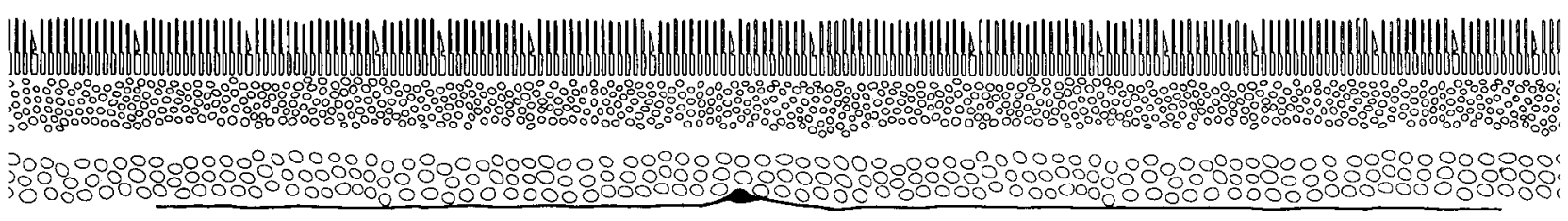

0000000000000000000000000000000000

Figure 1. Schematic representations of the retinal neurons studied. The largest group of indoleamine-accumulating cells is conventional amacrine cells $(t o p)$. Their dendrites form a dense plexus in layer 5 of the inner plexiform layer. From that plexus occasional stray processes (arrow) descend to run laterally within the optic fiber layer. Type 3 cells have dendrites in both the outer and inner plexiform layers. Displaced indoleamineaccumulating cells have virtually the same dendritic morphology as the conventional cells, but their cell bodies are located in the ganglion cell layer. The TH-positive cells are sparse amacrine cells with dendrites contained mainly in layer 1 of the inner plexiform layer. For more description, see Results; for details of the cells, see Figure 2 and the original articles (Sandell and Masland, 1986, 1989; Vaney, 1986; Tauchi et al., 1990).

but still very few in a retina that has roughly $5,000,000$ total amacrine cells (Vaney, 1991). To obtain comparable samples, we counted every TH-positive cell lying within a strip of retina $5 \mathrm{~mm}$ wide and running from the dorsal to the ventral extremes. This was done for four pairs of retinas. The density of the THpositive cells was found to vary little from animal to animal (Table 1).

\section{Stray processes}

From the plexus formed by the indoleamine-accumulating cells within the inner plexiform layer a few processes emerge on the vitreal side, cross the ganglion cell layer, and run across the retinal surface (Figs. 1,2). Some join with ganglion cell axons and run toward the optic nerve head. Many run a few hundred micrometers in the optic fiber layer and then reenter the inner plexiform layer, rejoining the plexus of stained dendrites formed by the indoleamine-accumulating cells. To count these processes, we sampled a series of horizontal transects crossing the retina from nasal to temporal. These were spaced at $0.5 \mathrm{~mm}$ intervals from the optic nerve to the retina's ventral boundary. Every intersection of a transect with an indoleamine-accumulating process in the optic fiber layer was counted, for five pairs 

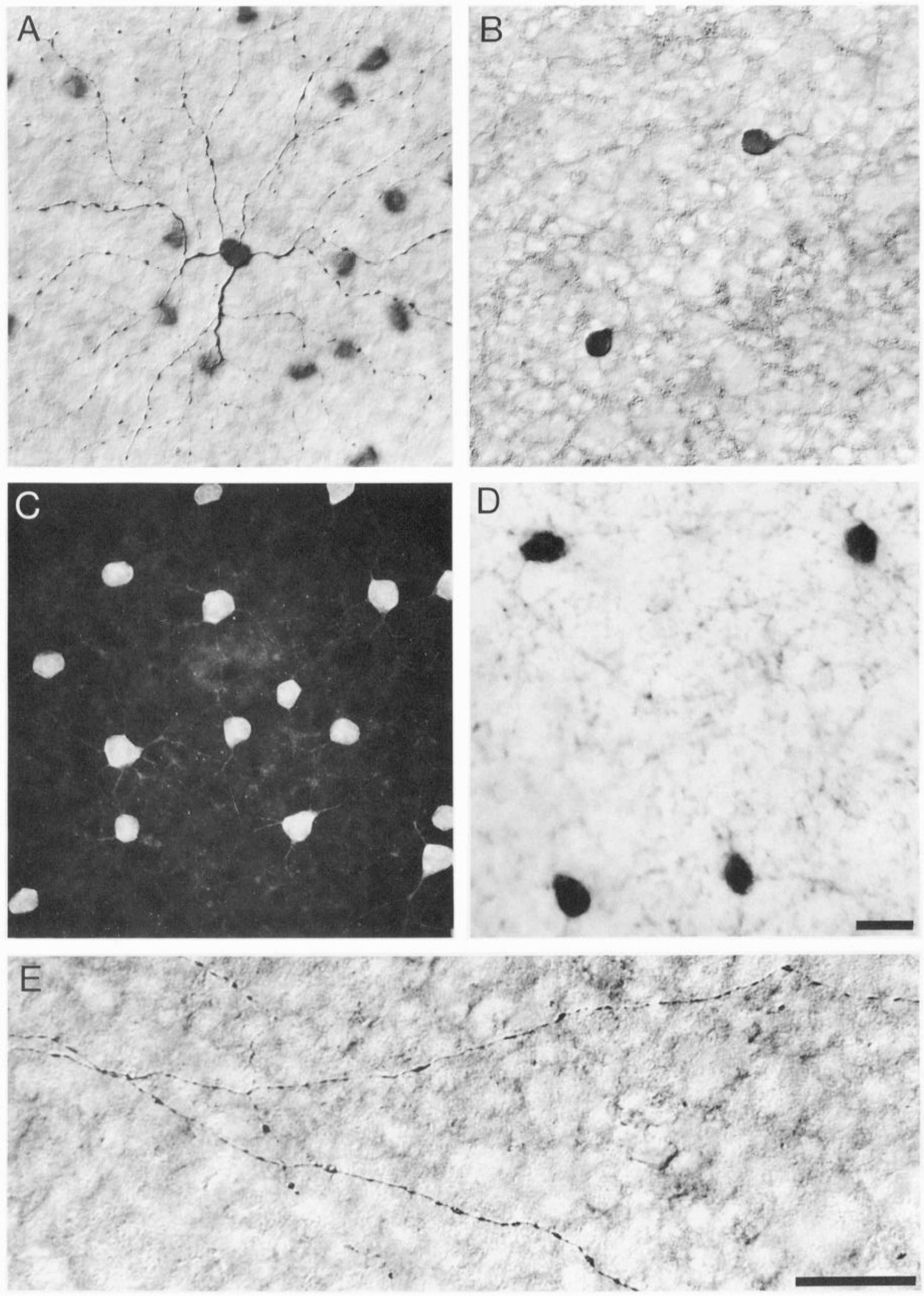

Figure 2. A, The distal arbor of a type 3 indoleamine-accumulating cell. The processes run within the outer plexiform layer. This cell also had an arbor in layer 5 of the inner plexiform layer. $B$, Cell bodies of displaced indoleamine-accumulating cells, lying in the ganglion cell layer. $C$, The mosaic of conventional indoleamine-accumulating amacrine cell bodies. They are located in the inner cell row of the inner nuclear layer. $D$, THpositive amacrine cells in the mouse retina. $E$, Stray processes of indoleamine-accumulating cells. These are located in the optic fiber layer. Scale bars, $20 \mu \mathrm{m}$ (scale bar in $D$ is for $A-D$ ). 

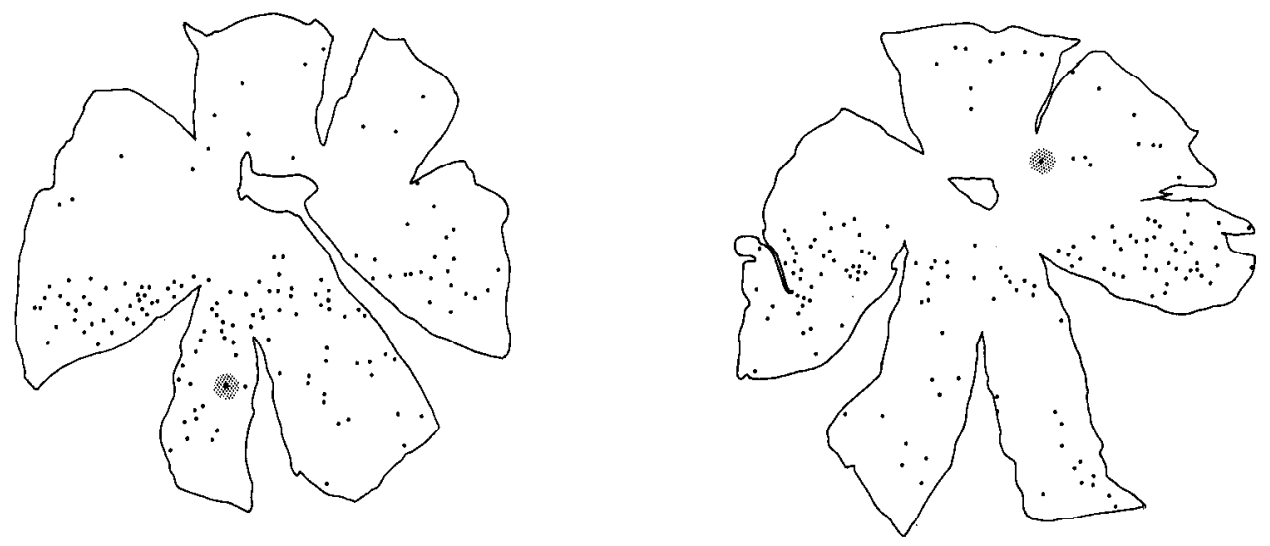

Displaced cells, rabbit
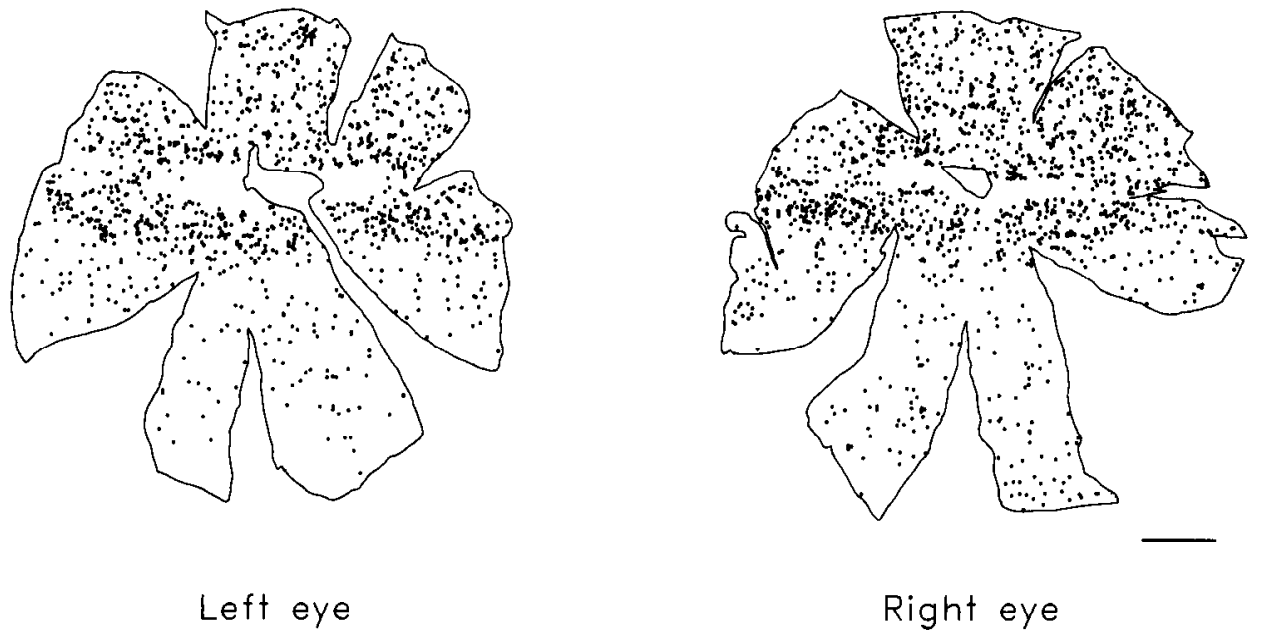

Figure 3. Maps of the distribution of type 3 cells and displaced cells. The position of each cell in the whole-mount is shown by a dot. Note that the type 3 cells are most frequent in the ventral retina, while displaced cells are commonest in the visual streak and dorsal retina. Cuts were made in the retinas to allow them to be flattened on slides. Scale bar, $4 \mathrm{~mm}$. of retinas. The mean number of intersections ranged from as many as 8.85 per millimeter in one retina to as few as 1.08 (Table 1). The numbers of stray processes in two eyes from the same animal, however, varied by only $22 \%$. The number of stray processes did not covary with the number of type 3 cells, displaced cells, or conventional cells.

\section{TH-containing amacrine cells in inbred mice}

For a comparison made in the absence of the genetic variability present in laboratory rabbits, we counted and plotted the positions of every TH-positive neuron in both retinas of seven C57BL/6J mice (Table 1, Figs. 5, 6). These varied less from animal to animal than any of the cells studied in rabbits. Even so, the variability that did exist behaved the same way as for the rabbit: two eyes of the same animal were closer in cell number than eyes taken from different animals (Fig. 6).

\section{Discussion}

In this work we have concentrated upon the variable structures stained by our methods. However, the variable structures are noticeable because the main cellular populations of the retina are present with truly spectacular reproducibility. A mouse retina contains in the order of $4,000,000$ total neurons. On average,
490 of these are TH-positive amacrine cells. The developmental program creates these 490 neurons with great fidelity. When two eyes of an inbred mouse are compared, eliminating most sources of genetic and environmental variability, the numbers of THpositive cells varied by only $2.5 \pm 1.7 \%$. A developmental program that generates $4,000,000$ retinal neurons specifies the population of TH amacrine cells with an average difference of only 12 cells.

In rabbits, the anomalous cells vary widely in number from animal to animal, but even these cells are created with good reproducibility. From eye to eye in the same animal, their numbers vary by roughly the same amount as the ordinary amacrine cells-roughly $12 \%$. Even this figure is surely too high, because it includes measurement error. The developmental program, then, is capable of generating very constant cell numbers. In that casc, how should onc think about the structures that do vary from animal to animal?

Type 3 cells, displaced indoleamine-accumulating cells, and stray indoleamine-accumulating cell processes would traditionally be called "developmental errors"

The phrase "developmental error" is rarely given an exact definition, but generally subsumes two concepts. One is that the 

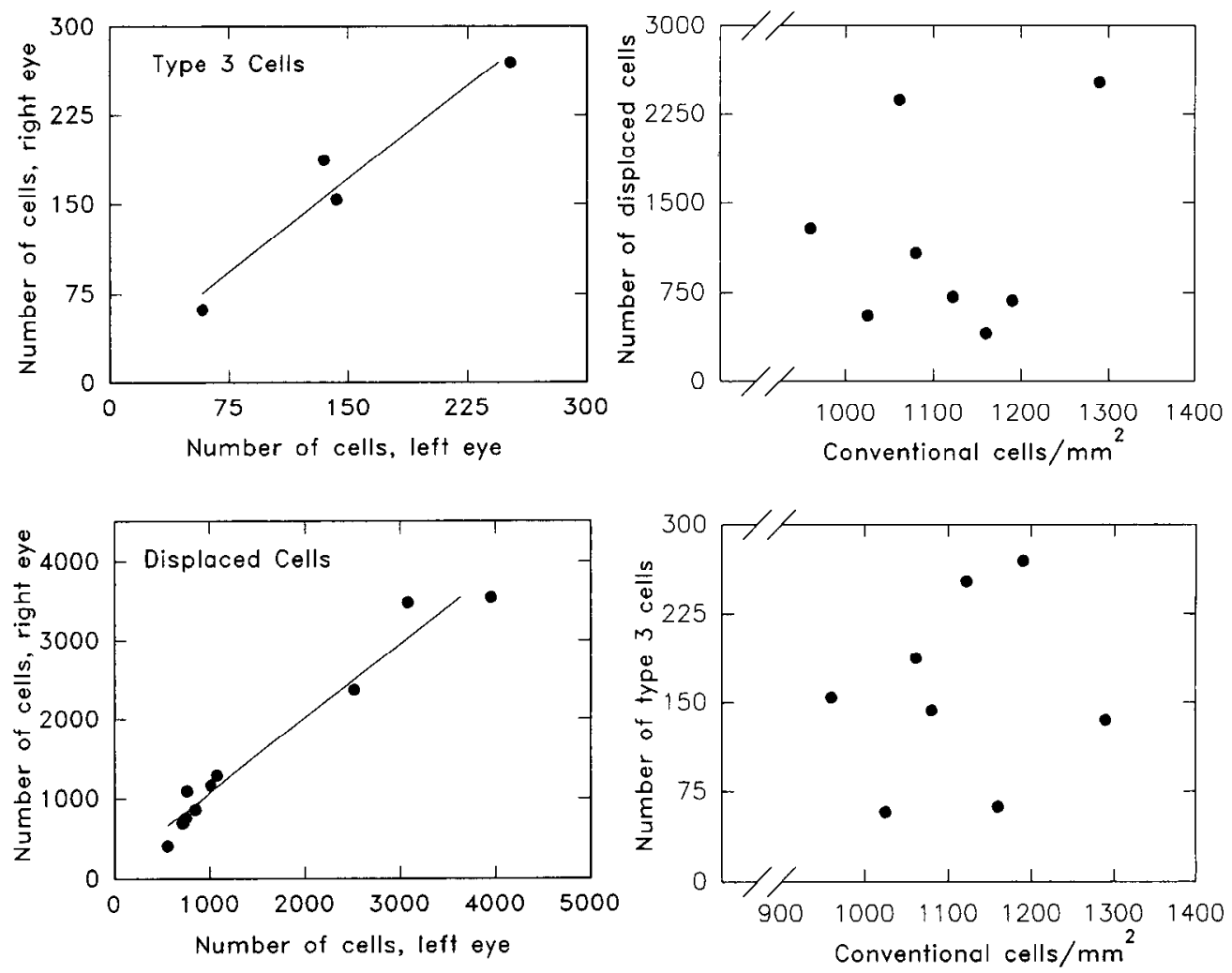

Figure 4. Cross-comparisons of the cells. The numbers of the cells or stray processes were very nearly the same from eye to eye of an individual animal. Within a single retina, however, the numbers of the aberrant elements did not correlate with each other.


event (usually a morphological one) is different from those observed in many other individuals of the same species. The second is that the structure created does not make sense functionally; an example might be an axon that runs to a clearly inappropriate target structure. The three aberrant structures fit both criteria. Although they are observed in all rabbit retinas, their variable number indicates that they are not part of the retina's standard functional circuitry. Moreover, they contrast dramatically with the great regularity of cellular pattern formation that is generally evident for retinal neurons. The latter has become particularly clear with the advent of methods that allow subpopulations of retinal neurons to be separately stained in whole-mounts. What is found is a strong tendency to orderliness. Separate studies have been made for color-specific subclasses of cones, rods, horizontal cells, rod bipolar cells, one class of cone bipolar cells, ganglion cells, and at least four subclasses of amacrine cells (Marc and Sperling, 1977; Wässle and Riemann, 1978; Wässle et al., 1981a-c; Tauchi and Masland, 1984; Sandell and Masland, 1986; Tauchi et al., 1990; Wikler and Rakic, 1990; Vaney, 1991; Vaney et al., 1991). The cells are found to be evenly spaced, so that nearest-neighbor analysis shows a measurable tendency to regularity. They also cover the retina completely. By this is meant that a given cell type is present everywhere across the retinal surface, with a dendritic field diameter wide enough that each point is overlain by at least one example of the cell in question..

Figure 3 shows the coverage of the retina by the type 3 cells of one of our animals. There are large gaps in the coverage, making it extremely unlikely that these cells have a function in visual processing. There is no known retinal activity with such a patchy distribution. As just noted, the retina is a modular structure, in which the same groupings of functional elements are repeated over and over across the retinal surface. The type 3 cells, with their irregular and sparse coverage, stand out to us and to others (Vaney, 1991; Wässle and Boycott, 1991) as deviant from the retina's general plan.

At the same time, they are not accidents

The type 3 cells (and the other two aberrant elements) are hardly accidental. They are present in all retinas. Furthermore, they 




Left eye

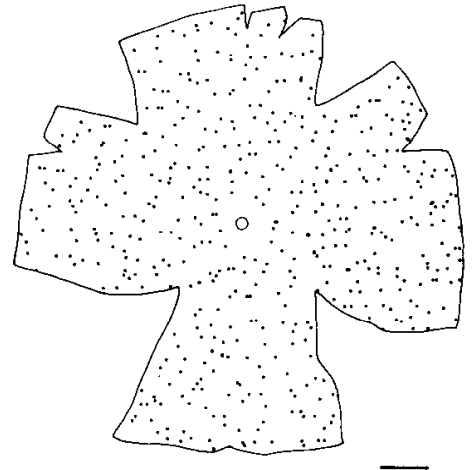

Right eye
Figure 5. The position of every $\mathrm{TH}$ positive cell in a pair of retinas from a mouse. Scale bar, $0.5 \mathrm{~mm}$. have just the same, highly distinctive structure in all retinas. The type 3 cells have a striking overall morphology, spanning between the inner plexiform layer and the outer, and they have highly reproducible dendritic arbors, with similar sizes and branching patterns. The shape of these cells is as constant as any other retinal neuron-and more constant than some that are recognized as regular members of the retina's complement of neurons.

Most important, the number of the cells is nearly the same in the two eyes of a single animal. This implies that the generation of these cells is under the control of a single developmental program, one that varies slightly from animal to animal.

The aberrant cells are systematically generated during development, but are not individually specified: on a cell-for-cell basis, two eyes from the same animal are not identical

Why are the numbers of aberrant cells so close in two eyes from the same animal? An extreme possibility would be that the development of the retina is tightly specified by fixed lineages. There is much evidence against such a mechanism (Turner and Cepko, 1987; Holt et al., 1988; Harris and Holt, 1990). In any event, fixed lineages would create in the two eyes cells that are not only identical in number but also in position. That was not the case. Although the numbers of aberrant structures in the two eyes of a given animal are very close, their locations were not identical, as may be seen by the absence of duplicate patterns in the locations of the type 3 cells or displaced cells for two eyes from the same animal (Fig. 3). Instead, whatever events create the type 3 cells create them in almost equal numbers without generating literal mirror images in the two eyes. The populations behave as though a particular animal had a bias toward the formation of one or the other aberrant neural structure, without rigidly specifying the existence of each such cell. [Note that such a bias applies separately to each of the three aberrant structures studied: the number of type 3 cells does not correlate with the number of displaced cells or stray indoleamine-accumulating cell processes (Table 1, Fig. 4).]

\section{How might the aberrant structures be generated?}

Many possibilities can be imagined. One is that the cells express a developmental program, unique to them, in which a series of development genes are coordinately expressed. These specify the distinctive shape (and possibly other characteristics) of the type 3 cells. The number of type 3 cells would vary because the number of cells expressing the regulatory gene or genes varies.

Such a highly specified mode of formation seems unlikely. The type 3 cells are virtually identical to the conventional indoleamine-accumulating amacrine cells; the main exception is that they have an arbor in the outer plexiform layer as well as the inner. Both types of cells express an indoleamine transporter and a GABA transporter (Sandell and Masland, 1989). The proximal processes of the type 3 cells run to the same location in the inner plexiform layer as those of the regular cells, where they turn laterally and intertwine indistinguishably with the processes of the regular amacrine cells. Even their arbor in the outer plexiform layer has much in common morphologically with the arbors of the regular indoleamine-accumulating cells, having roughly the same diameter and general branching pattern (Sandell and Masland, 1986, 1989; Vaney, 1986). Although the appearance of the type 3 cells seems at first quite different from that of the conventional cells, the difference is in fact slight. They are basically regular cells with a supernumerary arbor in the outer plexiform layer. Most of the regular indoleamineaccumulating cell phenotype is preserved.

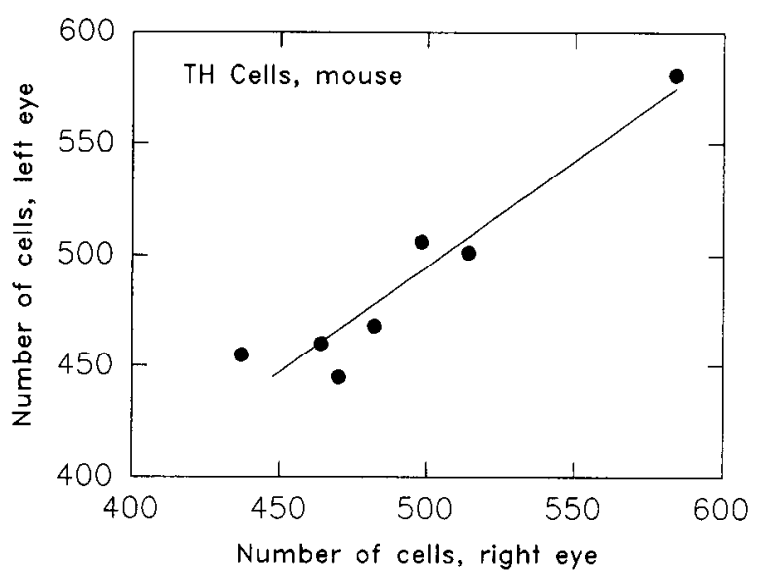

Figure 6. Numbers of TH cells in mice. The number of TH cells varied little within the two eyes of a single mouse. There was some variation from animal to animal, though much less than for the aberrant cells studicd in the rabbit retina. 
How might these arbors be formed? A clear possibility is that the cells become inappropriately sensitive to a developmental attractant in the outer plexiform layer. This could be a diffusible substance, a cell surface marker, or a molecule located in the extracellular matrix. Once under the control of the outer plexiform signal the development of a dendritic arbor would continue but in an inappropriate place. An attractively simple exposition of such a mechanism has been given to account for misplaced axonal growth in C. elegans (White, 1985; White et al., 1986). In that case the argument is made on the basis of positional error: the processes are said to be located in the "wrong neighborhood" at a crucial time in the developmental sequence; process outgrowth then follows normally present molecular markers down a path appropriate for other cells but not the misplaced ones.

Other alternatives can be imagined. For example, the type 3 cells could overexpress a receptor for a diffusible attractant molecule present in the outer plexiform layer. They could be residual pioneer neurons that are usually eliminated when their pioneer function is over. They could be cells that failed to complete a prenatal migration to the base of the inner nuclear layer. The point here is not which mechanism is correct; it is that all three abcrrant structures may be accounted for by very simple developmental events, which alter the developmental history of the respective cells but leave unchanged most of the cells' developmental program and eventual phenotypes.

\section{Small deviations in developmental control can create intricate and well-organized neuronal phenotypes}

The developmental errors previously described are sometimes clearly nonfunctional; the missing branch of $C$. elegans' RMFR motor neuron would have contained all of its neuromuscular junctions, and thus deprives the neuron of its normal output (White et al., 1986). Similarly, stray processes of the indoleamine-accumulating cell end at seemingly random locations across the retinal surface-locations where it is hard to imagine them having a meaningful function. However, the aberrant nature of the type 3 cells is only evident when their sparse and irregular distribution and intra-animal variability are known. Taken one cell at a time, they look like normal retinal neurons. Were there 2000 of them per retina rather than 200 , we and others might well be seeking to learn their function (they would probably be considered a subtype of bipolar cell).

Indeed, one can imagine that if type 3 cells provided a selective advantage, they would eventually become a regular and consistent part of the retina's circuitry. Perhaps the aberrant structures described here reflect a mechanism by which complex neural structures can evolve. If, as we have argued, these cells are the result of very small changes in the genetic program, they suggest a mechanism by which small mutational events could help create the intricate final circuitry of the normal mammalian brain.

\section{References}

Brecha NC (1983) Retinal neurotransmitters: histochemical and biochemical studies. In: Chemical neuroanatomy (Emson PC, ed), pp 85-129. New York: Raven.

Brecha NC, Oyster CW, Takahashi ES (1984) Identification and characterization of tyrosine hydroxylase immunoreactive amacrine cells. Invest Ophthalmol Vis Sci 25:66-70.

Ehinger $\mathrm{B}$ (1976) Biogenic monoamines as transmitters in the retina. In: Transmitters in the visual process (Bonting SL, ed), pp 145-163. Oxford: Pergamon.
Ehinger B, Florén I (1976) Indoleamine accumulating neurons in the retina of rabbit, cat, and goldfish. Cell Tissue Res 175:37-48.

Goodman CS (1977) Neuron duplications and deletions in locust clones and clutches. Science 197:1384-1386.

Harris WA, Holt CE (1990) Early events in the embryogenesis of the vertebrate visual system: cellular determination and pathfinding. Annu Rev Neurosci 13:155-169.

Holt CE, Bertsch TW, Ellis HM, Harris WA (1988) Cellular determination in the Xenopus retina is independent of lineage and birth date. Neuron 1:15-26.

Macagno ER (1980) Number and distribution of ncurons in lccch segmental ganglia. J Comp Neurol 190:283-302.

Marc RE, Sperling HG (1977) Chromatic organization of primate cones. Science 196:454-456.

Mariani AP (1991) Synaptic organization of type 2 catecholamine amacrine cells in the rhesus monkey retina. J Neurocytol 20:332342.

Masland RH (1988) Amacrine cells. Trends Neurosci 11:405-410.

Oyster CW, Takahashi ES, Cilluffo M, Brecha NC (1985) Morphology and distribution of tyrosine hydroxylase-like immunoreactive neurons in the cat retina. Proc Natl Acad Sci USA 82:6335-6339.

Sandell JH, Masland RH (1986) A system of indoleamine-accumulating neurons in the rabbit retina. J Neurosci 6:3331-3347.

Sandell JH, Masland RH (1989) Shape and distribution of an unusual retinal neuron. J Comp Neurol 280:489-497.

Sandell JH, Masland RH, Raviola E, Dacheux RF (1989) Connections of indoleamine-accumulating cells in the rabbit retina. J Comp Neurol 283:303-313.

Tauchi M, Masland RH (1984) The shape and arrangement of the cholinergic neurons in the rabbit retina. Proc R Soc Lond [Biol] 223: 101-119.

Tauchi M, Madigan NM, Masland RH (1990) The shapes and distributions of the catecholamine-accumulating neurons in the rabbit retina. J Comp Neurol 293:178-189.

Turner DL, Cepko C (1987) A common progenitor for neurons and glia persists in rat retina late in development. Nature 238:131-136.

Vaney DI (1986) Morphological identification of serotonin-accumulating neurons in the living retina. Science 233:444-446.

Vaney DI (1991) The mosaic of amacrine cells in the mammalian retina. Prog Retinal Res 9:1-28.

Vaney DI, Gynther IC, Young HM (1991) Rod-signal interneurons in the rabbit retina. 2. AII amacrine cells. J Comp Neurol 310:154169.

Voigt T, Wässle H (1987) Dopaminergic innervation of A II amacrine cells in mammalian retina. J Neurosci 7:4115-4128.

Wässle H, Boycott BB (1991) Functional architecture of the mammalian retina. Physiol Rev 71:447-480.

Wässle H, Riemann HJ (1978) The mosaic of nerve cells in the mammalian retina. Proc R Soc Lond [Biol] 200:441-461.

Wässle H, Peichl L, Boycott BB (1978) Topography of horizontal cells in the retina of the domestic cat. Proc R Soc Lond [Biol] 203:269291.

Wässle H, Peichl L, Boycott BB (1981a) Dendritic territorics of cat retinal ganglion cells. Nature 292:344-345.

Wässle H, Peichl L, Boycott BB (1981 b) Morphology and topography of on- and off-alpha cells in the cat retina. Proc R Soc Lond [Biol] 212:157-175.

Wässle H, Peichl L, Boycott BB (1981c) Morphology and mosaic of on- and off-beta cells in the cat retina and some functional considerations. Proc R Soc Lond [Biol] 212:177-195.

Wässle H, Yamashita M, Greferath U, Grünert U, Muller F (1991) The rod bipolar cell of the mammalian retina. Vis Neurosci 7:99112.

White JG (1985) Neuronal connectivity in Caenorhabditis elegans. Trends Neurosci 8:277-283.

White JG, Southgate E, Thomson JN, Brenner S (1986) The structure of the nervous system of the nematode Caenorhabditis elegans. Philos Trans R Soc Lond [Biol] 314:1-340.

Wikler KW, Rakic P (1990) Distribution of photoreceptor subtypes in the retina of diurnal and nocturnal primates. J Neurosci 10:33903401 .

Williams RW, Herrup K (1988) The control of neuron number. Annu Rev Neurosci 11:423-453. 